\title{
ANÁLISE TEMPOROESPACIAL DA COBERTURA VEGETAL DO BAIRRO TENONÉ - BELÉM/PA
}

Marlisson Lopes de Araújo'; Luziane Mesquita da Luz²; José Edilson Cardoso Rodrigues ${ }^{3}$

(recebido em 04.07.2011 e aceito para publicação em 15.03.2012)

\section{RESUMO}

O trabalho analisou o processo de urbanização na área de expansão urbana de Belém a partir da década de 1980 e suas implicações na configuração temporal e espacial da cobertura vegetal do bairro Tenoné/Belém-PA. Para tanto, realizamos um levantamento teórico, pesquisas de campo, e uso de imagens de satélite e ortofotos da cidade de Belém do período 1998-2010. Os dados coletados e analisados nos levam ao entendimento que o Tenoné apresenta uma grande quantidade de cobertura vegetal para os anos de 1998 (54,09\%), $2006(41,98 \%)$ e 2010 (36,12\%), levando em consideração a quantidade de cobertura vegetal por habitante o índice também se manteve bem acima do recomendável para os três anos sendo que, para o ano de 1998 foi de 223,64m²/hab., para 2006 foi de 173,56m²/hab. e para o ano de 2010 esse índice foi de 149,35m²/hab. Apesar dos altos índices quantificados no bairro cabe aqui ressaltar que o mesmo vem sofrendo intenso processo de ocupação e conseqüente retração da cobertura vegetal.

Palavras-Chave: Urbanização; Arborização urbana; Planejamento urbano; Áreas verdes.

\footnotetext{
1 Acadêmico do curso de Geografia (Licenciatura) do Instituto Federal do Pará - IFPA marlissonaraujo@hotmail.com

2 Professora Msc da Universidade Federal do Pará - UFPA- Belém-PA e orientadora do artigoluzianeluz@yahoo.com.br

${ }_{3}$ Professor Msc da Universidade Federal do Pará - UFPA- Belém-PA e orientador do artigo jecrodrigues@yahoo.com.br
} 


\section{TEMPORAL AND \\ SPATIAL TEMPORAL ANALYSIS OF VEGETATION OF TENONÉ - BELÉM / PA}

\section{ABSTRACT}

This study analyzed the urbanization process of the urban expansion area of Belém from the 1980s and their implications for temporal and spatial configuration of vegetation in the Tenoné / Belém-PA. Therefore, we made a theoretical study, a field research, and the use of satellite images and orthophotos from Belem (1998-2010). The collected and analyzed data lead us to understand that Tenoné has a large amount of vegetation in the years of 1998 (54.09\%), 2006 (41.98\%) and 2010 (36.12\%). Considering the amount of vegetation per capita, the index also remained above the recommended for this three years and in the year of 1998 this index was $223.64 \mathrm{~m}^{2} / \mathrm{hab}$, in 2006, it was $173.56 \mathrm{~m}^{2} /$ hab and in 2010 this index was $149.35 \mathrm{~m}^{2} /$ hab. Although the high rates quantified in the neighborhood, this study emphasizes this area is passing through an intense process of occupation and subsequent retraction of the vegetation.

Keywords: Urbanization; Urban vegetation; Urban planning; Vegetation.

\section{INTRODUÇÃO}

Desde muito tempo, o homem vem trocando o meio rural pelo meio urbano. As cidades foram crescendo, na maioria das vezes de forma muito rápida e desordenada, sem um planejamento adequado de ocupação, provocando vários problemas que interferem sobremaneira na qualidade de vida do homem que vive na cidade. "Atualmente, a maioria da população humana vive no meio urbano necessitando, cada vez mais, de condições que possam melhorar a convivência dentro de um ambiente muitas vezes adverso" (PIVETTA E SILVA FILHO, 2002, p.1).

A arborização urbana atua sobre o conforto humano no ambiente por meio das características naturais das árvores, proporcionando sombra para pedestres e veículos, redução da poluição sonora, melhoria da qualidade do ar, redução da amplitude térmica, 
abrigo para pássaros e equilíbrio estético, que ameniza a diferença entre a escala humana e outros componentes arquitetônicos como prédios, muros e grandes avenidas.

Adequar o espaço urbano á vegetação pré-existente demonstraria ser uma decisão coerente, tendo em vista que estas espécies por serem autóctones ${ }^{4}$ têm rusticidade e resistência propícia ao ambiente. Além de contribuir para a conservação da flora regional. Entretanto, boa parte dos planejadores opta pela introdução de espécies exóticas, talvez pelo maior conhecimento a respeito da funcionalidade destas, ou mesmo por apresentarem certa apreensão em relação às nativas, "apresentando assim, um predomínio de espécies exóticas em praticamente todas as cidades do país" (IWATA ET AL, 2007, p.2). A vegetação, pelos vários benefícios que pode proporcionar ao meio urbano, tem um papel muito importante no restabelecimento da relação entre a sociedade e o meio natural, garantindo melhor qualidade de vida.

Dentre os fatores que interferem na qualidade ambiental das cidades a cobertura vegetal desempenha importantes funções ecológicas e sócio-educativas. A redução da vegetação nas áreas urbanas, normalmente para ceder espaço às construções e diversas formas de impermeabilização do solo, pode gerar vários problemas destacando-se alterações climáticas e suas conseqüências (assoreamento de rios, enchentes, "ilhas de calor", etc.). A distribuição espacial, juntamente com a quantidade e as características, da cobertura vegetal oferece importante parâmetro para avaliação da qualidade ambiental urbana.

"Estudos estimaram que um índice de cobertura vegetal em torno de 30\% (da área) seja recomendável para proporcionar um adequado balanço térmico em áreas urbanas" (VENTURA E FAVERO 2005, p.784). Outros estudos verificaram que a predominância de manchas de vegetação maiores e com conexões (com menor fragmentação) favorece os benefícios por ela oferecidos e a manutenção da biodiversidade.

Segundo Bezerra (2008, p.2) "o estudo da qualidade ambiental permite entendermos melhor o que ocorre quando a ação antrópica intensifica as inter-relações dos componentes biológicos e geográficos presentes na paisagem". Tal processo de transformação encontrado no ambiente está relacionado na maioria das vezes a fatores espaciais modificados pela ação do homem. "Equilíbrio ambiental", "cidades sustentáveis", "efeitos negativos sobre o meio ambiente", "poluição e degradação ambiental", "limites da

\footnotetext{
${ }^{4}$ Espécies endêmicas da região amazônica.
}

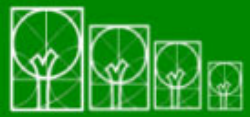

$\mathbf{S} \cdot \mathbf{B} \cdot \mathbf{A} \cdot \mathbf{U}$ Soc. Bras. de Arborização Urbana 
sustentabilidade ambiental" e proteção, preservação e recuperação do meio ambiente natural, entre outros temas encontrados no Estatuto da Cidade, dizem respeito ao "verde urbano" que, apesar de sua importância, não se apresenta como uma necessidade óbvia na cena urbana, sendo negligenciado no planejamento do desenvolvimento das cidades. "Todavia, a necessidade que o homem tem de vegetação extrapola um valor meramente sentimental ou estético, desempenhando também um importante papel nas áreas urbanizadas no que se refere à qualidade ambiental" (MONTEIRO, 1976 Apud BUCCHERI FILHO E NUCCI, 2006, p.49).

No que concerne a atual região metropolitana de Belém (ARMB), podemos observar - avanço da expansão urbana de maneira desordenada, problema esse também evidenciado em outras grandes cidades brasileiras, onde as ocupações e as diversas maneiras de usos do solo consolidam a maneira de relação da sociedade e natureza como degradante, sobretudo no que podemos nos referir à perda de cobertura vegetal nas áreas centrais da cidade como também em áreas de expansão urbana, refletindo na diminuição de áreas verdes.

Tendo em vista esse problema, evidencia-se preocupante a perda da cobertura vegetal e os efeitos negativos desta sobre a qualidade de vida da população urbana, pois a vegetação possui um papel importante para o bem estar da população. "As árvores, por suas características naturais, proporcionam muitas vantagens ao homem que vive na cidade, sob vários aspectos" (PIVETTA E SILVA FILHO 2002, p.2).

Como obstáculo contra o vento, proteção da qualidade da água, purificação do ar, equilíbrio do índice de umidade, diminuição da poeira em suspensão, redução dos ruídos, interação entre as atividades humanas e o meio ambiente, fornecimento de alimentos, proteção das nascentes e mananciais, organização e composição de espaços no desenvolvimento das atividades humanas, valorização visual e ornamental, segurança nas calçadas (acompanhamento viário), recreação, quebra da monotonia das cidades, cores relaxantes, estabelecimento de uma escala intermediária entre a humana e construída, caracterização e sinalização de espaços, etc. (NUCCl e CAVALHEIRO, 1999, p.30).

Trabalhos realizados na cidade de Belém constataram que a retração da cobertura vegetal pode ter efeito significativo na vida da população residente nos bairros e nos distritos onde foram feitos os levantamentos. Segundo Luz e Rodrigues (2006, p.2) "a localização geográfica da cidade de Belém é caracterizada por uma grande quantidade de insolação o ano todo, sendo que, com a perda das áreas verdes o processo natural de evapotranspiração diminui rapidamente aumentando a temperatura da cidade".

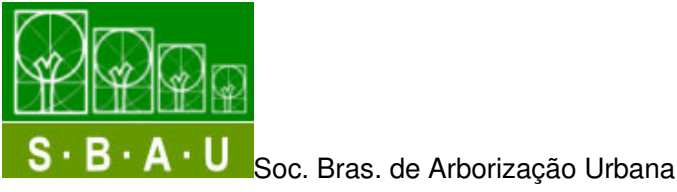

REVSBAU, Piracicaba - SP, v.7, n.1, p. 52-75, 2012 
Nos estudos realizados por Luz e Rodrigues (2006) nos Distritos Administrativos de Belém (DABEL), Distrito Administrativo da Sacramenta (DASAC) e no Distrito Administrativo do Guamá (DAGUA), verificou-se uma perda significativa de cobertura vegetal nos referidos distritos. Neste estudo todos os distritos apresentaram índice de cobertura vegetal abaixo de $30 \%$, que segundo Oke (1973) apud Lombardo (1985) é o recomendável para um adequado balanço térmico na cidade, somente o DABEL apresentou características favoráveis no que concerne um balanço térmico adequado com cerca de $29,39 \%$ de vegetação.

Diante da problemática exposta sobre cobertura vegetal em nível distrital, atenta-se para o trabalho sobre a vegetação do bairro Tenoné, localizado no Distrito Administrativo de Icoaraci (DAICO), no município de Belém-PA, onde serão analisadas as questões relacionadas à perda de cobertura vegetal e sua modificação espacial ao longo de seu processo histórico de ocupação.

O presente trabalho faz parte de um projeto maior, intitulado "Estudo e valorização das áreas verdes urbanas na cidade de Belém-Pa" desenvolvido pela faculdade de Geografia e Cartografia da UFPA.

Neste sentido levantamos as seguintes hipóteses:

a) O bairro Tenoné vem perdendo gradativamente sua cobertura vegetal original em virtude do intenso processo de expansão urbana. Essa intensa ocupação pode contribuir para a diminuição do índice de cobertura vegetal e aumentar o desconforto térmico no bairro.

b) O bairro não possui infra-estrutura adequada para uma boa qualidade de vida da população residente. Atualmente é alvo de intensa ocupação espontânea que de certa forma moldam o espaço a partir da ação coletiva, essas ocupações não possuem infraestrutura mínima de áreas verdes - ruas arborizadas, praças e parques públicos.

c) Os atores modeladores do espaço: Estado, iniciativa privada, população fazem do bairro Tenoné um campo de lutas, lutas essas que se reflete no espaço segregado e compartimentado a partir de interesses de cada ator.

O crescimento horizontal da capital paraense iniciado a partir da década de 1980, tendo como uma de suas direções a Rodovia Augusto Montenegro, considerada uma área de expansão urbana e um dos principais vetores de ocupação, atingiu sobremaneira a configuração espacial do bairro Tenoné, principalmente residencial (CORRÊA e COSTA, 2009). O bairro, pertencente ao distrito administrativo de Icoaraci vem sofrendo nos últimos anos um processo de ocupação muito intensa devido sua localização na periferia da cidade, 
neste sentido vem sendo lócus de muitas empresas de construção civil na implantação de projetos habitacionais em condomínios horizontais fruto da descentralização da política habitacional da cidade de Belém.

Dentre outras formas o bairro também vem se expandindo devido aos programas habitacionais horizontais de casas populares promovidos pela Companhia de Habitação do Estado do Pará (COHAB), sendo que no bairro Tenoné também podemos encontrar ocupações espontâneas ${ }^{5}$ sem nenhuma infra-estrutura, o que põe em cheque a retração da cobertura vegetal e a qualidade de vida da população residente neste local.

A urbanização desordenada causa problemas ecológicos: o desequilíbrio crescente entre a população e os meios materiais e, em troca, a contaminação em todas as suas manifestações. A natureza humanizada, através das modificações do ambiente, alcança maior expressão nos espaços ocupados pelas cidades criando um ambiente artificial (LOMBARDO, 1985, p. 16).

Nesse sentido, realizamos um estudo com a finalidade de quantificar a perda de cobertura vegetal no período de 1998-2010, além de analisar a forma e configuração espacial em função do processo de ocupação.

\section{Políticas públicas em Belém}

Art. 30 A Política Municipal de Saneamento Ambiental Integrado tem como objetivos manter o meio ambiente equilibrado, alcançando níveis crescentes de salubridade, e promover a sustentabilidade ambiental do uso e ocupação do solo, visando à melhoria das condições de vida da população.

Parágrafo único. O modelo de intervenção adotado pela Política Municipal de Saneamento Ambiental Integrado deve associar as atividades da gestão ambiental, o abastecimento de água potável, o uso racional da água, a coleta e o tratamento de águas residuárias, a drenagem de águas pluviais, o manejo dos resíduos sólidos e a educação sanitária e ambiental (Plano Diretor do Município de Belém, 2008, p. 20).

De acordo com o plano diretor a grande maioria das atribuições que são discutidas nele não é encontrada no bairro Tenoné, principalmente com relação ao planejamento e

\footnotetext{
${ }^{5}$ Áreas de ocupação espontânea ou invasões como são conhecidas na cidade são os novos espaços de assentamentos surgidos a partir da década de oitenta que ratificam a nova face do processo de reestruturação metropolitana que se caracteriza pela dispersão da cidade, sobretudo na área de expansão urbana, mais ocorrem também na periferia da área central (TRINDADE JR, 1998. APUD LUZ E RODRIGUES, 2006).
}

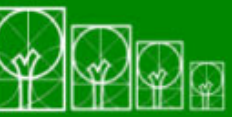

$\mathbf{S} \cdot \mathbf{B} \cdot \mathbf{A} \cdot \mathbf{U}$ Soc. Bras. de Arborização Urbana

REVSBAU, Piracicaba - SP, v.7, n.1, p. 52-75, 2012 
ordenamento do uso do solo, pois existem inúmeros problemas ambientais com relação à construção de moradias irregulares em torno dos igarapés que drenam o local em estudo.

Art. 53 A Política Municipal de Meio Ambiente tem como objetivo garantir o direito da coletividade ao meio ambiente sadio e ecologicamente equilibrado, promovendo a sustentabilidade ambiental do uso do solo urbano e rural, de modo a compatibilizar a sua ocupação com as condições exigidas para a conservação, preservação e recuperação dos recursos naturais e a melhoria da condição de vida da população (Plano Diretor do Município de Belém, 2008, p. 32).

Art. 57 Fica criado o Sistema Municipal de Áreas Verdes e de Lazer composto por:

I - áreas verdes públicas ou privadas significativas, parques e unidades de conservação;

II - Áreas de Preservação Permanente (APP), assim definidas no artigo $2^{\circ}$ da Lei no 4.771, de 15 de setembro de 1965, que institui o Código Florestal Brasileiro e suas alterações, e que integram as bacias hidrográficas do Município de Belém;

III - áreas públicas ou privadas, em situação de degradação ambiental;

IV - áreas naturais preservadas em função da existência de populações tradicionais.

Art. 58 O Sistema Municipal de Áreas Verdes e de Lazer tem como objetivos:

I - assegurar usos compatíveis com a preservação e proteção ambiental nas áreas integrantes do sistema;

II - adotar critérios justos e eqüitativos de provisão e distribuição das áreas verdes e de lazer no âmbito municipal;

III - definir critérios para a vegetação a ser empregada no paisagismo urbano, garantindo sua diversificação;

IV - garantir a multifuncionalidade das unidades por meio do tratamento paisagístico a ser conferido às mesmas;

$\mathrm{V}$ - ampliar os espaços de lazer ativo e contemplativo, criando parques lineares ao longo dos cursos d'água não urbanizados;

$\mathrm{VI}$ - integrar as áreas verdes de interesse paisagístico, protegidas ou não, de modo a garantir e fortalecer sua condição de proteção e preservação;

VII - ampliar e articular os espaços de uso público, em particular os arborizados e destinados à circulação e bem-estar dos pedestres;

VIII - garantir as formas tradicionais de organização social relacionada com recursos naturais preservados (Plano Diretor do Município de Belém BELÉM, 2008, p.33 e 34).

Não existe no bairro uma política de fomento de criação de áreas verdes e de lazer por parte do poder público ficando apenas concentrada nas áreas centrais da cidade ou muitas vezes no papel a criação desses espaços. O Tenoné não possui critérios de seleção da vegetação a ser empregada no paisagismo local e muito menos a articulação de espaços de uso público arborizados.

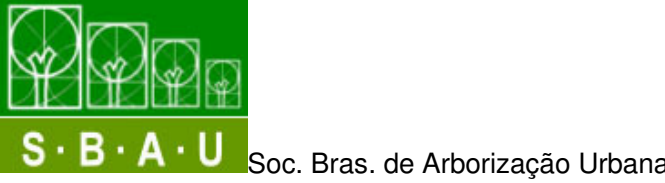

REVSBAU, Piracicaba - SP, v.7, n.1, p. 52-75, 2012 
É importante salientar que esses problemas fazem parte do cotidiano da população que vive no bairro Tenoné, porém é preciso que a sociedade seja esclarecida sobre as reais funções da cobertura vegetal e de áreas verdes de lazer no espaço urbano, uma vez que esses espaços são fundamentais para manter o equilíbrio ambiental. Neste sentido, é preciso à adoção de políticas públicas efetivas na manutenção e implementação desses espaços, pois a vegetação é um elemento importante para a qualidade de vida.

\section{MATERIAIS E MÉTODOS}

A área em estudo corresponde à área periférica do município de Belém pertencendo ao Distrito Administrativo de Icoaraci (DAICO) localizado em coordenadas geográficas de $1^{\circ}$

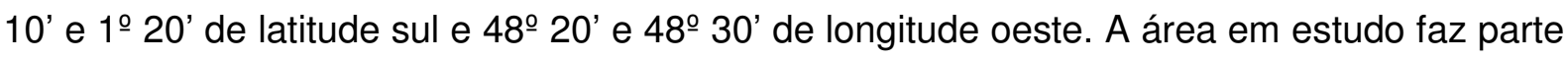
dos nove bairros correspondente ao DAICO são eles: Agulha, Águas Negras, Cruzeiro, Maracacuera, Paracurí, Ponta Grossa e Tenoné.

Faz limites a Leste com o rio Maguarí, a Norte com o bairro Águas Negras, a Oeste com o bairro Parque Guajará e a Sul faz limite com o bairro Coqueiro. Nas imediações do bairro pode ser encontrado o Palácio dos Despachos do Estado do Pará, a Secretaria de educação SEDUC, o Centro de processamento de Dados do Governo do Pará - PRODEPA e o Centro Operacional das Centrais Elétricas do Pará- CELPA.

A figura 1 mostra a localização da área em estudo na escala de 1:20.000 elaborado a partir dos dados da base cartográfica do cadastro Técnico dos bairros de Belém/PA. 
Figura 1 - Mapa de Localização do Bairro do Tenoné no Município de Belém/PA

Figure 1 - Location map of the Tenoné in the city of Belém/PA

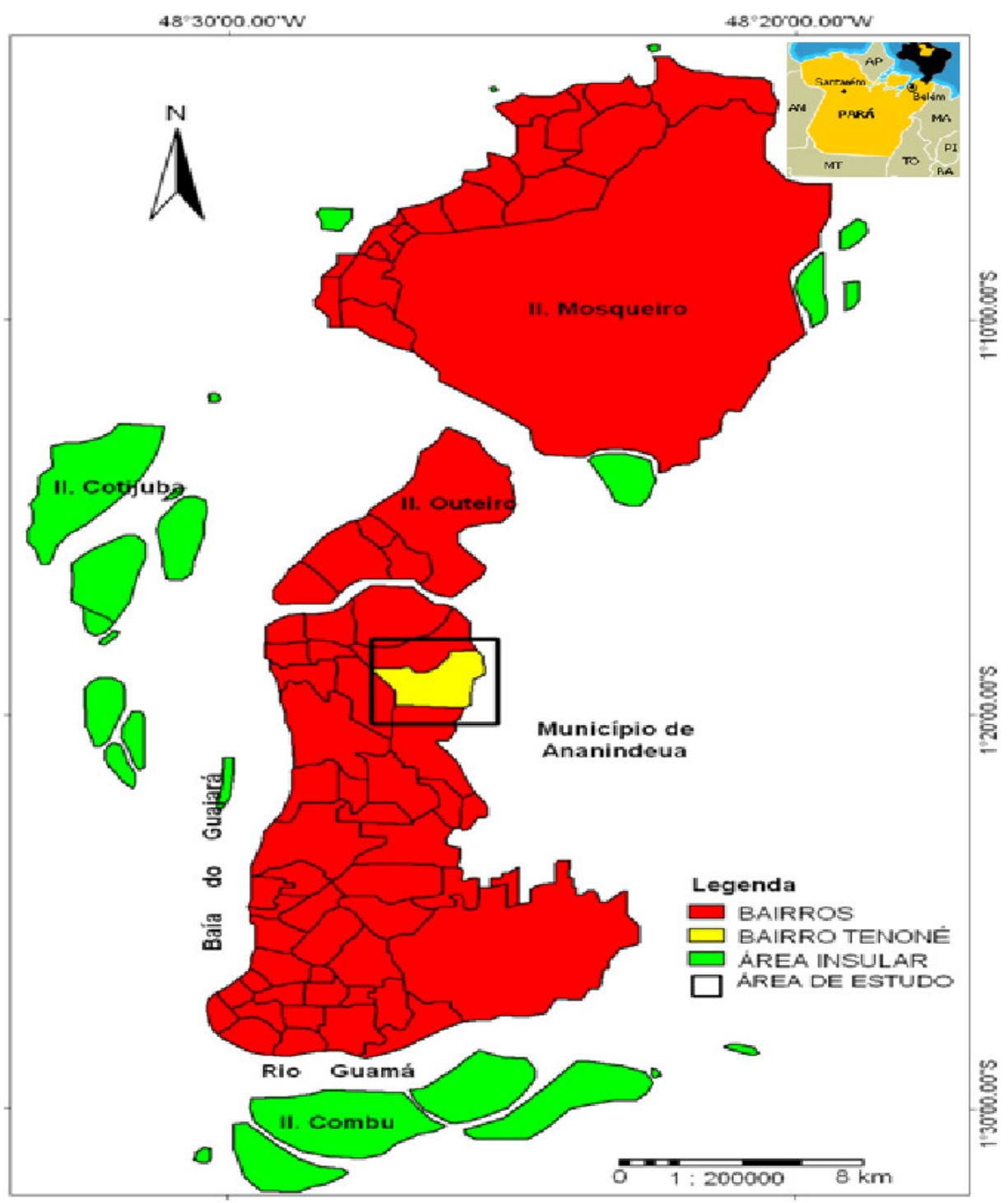

Fonte: Base cartográfica do Cadastro Técnico Multifinalitário - PMB.

Projeção UTM; DATUM SAD 69.

Nos estudos preliminares, realizamos levantamento bibliográfico e cartográfico, em acervos de instituições públicas (COHAB, SEGEP, SEURB, CODEM, IBGE, Prefeitura Municipal de Belém (agencia distrital de Icoaraci), UFPA), com o objetivo de obter dados referentes à demografia do bairro, histórico de ocupação e material cartográfico sobre a área de estudo.

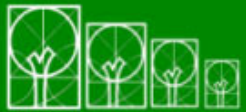

S $\cdot \mathbf{B} \cdot \mathbf{A} \cdot \mathbf{U}$ Soc. Bras. de Arborização Urbana 
O segundo passo foi a realização do reconhecimento do bairro em estudo, levando em consideração as seguintes informações:

- Delimitação da área de estudo através de imagens de satélite, fotografias aéreas de alta resolução espacial.

- Trabalhos de campo no período equivalente a Março de 2010 a janeiro de 2011.

As análises de campo foram muito importantes neste trabalho, pois possibilitaram uma observação mais aguçada dos elementos que compõe a paisagem urbana do bairro Tenoné. Os elementos do espaço natural da área analisada na pesquisa contemplaram a caracterização do mosaico vegetacional, como também o processo de ocupação e o uso do solo. Registramos através de fotografias in loco os elementos naturais e construídos (artificiais), que possibilitaram uma comparação das diferentes formas de ocupação do bairro Tenoné.

No terceiro passo foi realizado o mapeamento e analise da configuração espacial da cobertura vegetal, neste sentido para o reconhecimento e a delimitação territorial foi utilizada imagem de satélite $\operatorname{lkonos}^{6}$ 2006. Para validação da dimensão dos limites do bairro foram também analisados mapas cartográficos na escala de 1: 50.000 cedidos pela Secretaria Municipal de Coordenação Geral do Planejamento e Gestão (SEGEP). Através da imagem de satélite juntamente com os trabalhos de campo foi possível a realização dos mapas de cobertura vegetal dos anos de 1998, 2006 e 2010 na escala de 1:25.000. A elaboração desses mapas foi realizada por meio do programa computacional ILWIS CLIENT 3.2.

Para a configuração espacial da vegetação utilizou-se o modelo Tree-canopy cover construído por Jim, C Y (1989) que identifica três modelos de classificações do verde urbano: isolada, linear e conectada (ver figura 2).

\footnotetext{
${ }^{6}$ O satélite IKONOS II foi lançado no dia 24 de Setembro de 1999, e está operacional desde o início de janeiro de 2000. Ele é operado pela SPACE IMAGING que detém os Direitos de Comercialização em todo o mundo fora da Índia. Altitude de $680 \mathrm{Km}$; Inclinação de 98,1ㅜ; velocidade $7 \mathrm{Km} / \mathrm{s}$; Sentido da órbita descendente; Duração da órbita 98 minutos; Tipo de órbita sol-sincrona; Resolução espacial pancromática $1 \mathrm{~m} /$ multiespectral $4 \mathrm{~m}$;Imageamento $13 \mathrm{Km}$ na vertical (cenas de $13 \mathrm{Km} \times 13 \mathrm{Km}$ ); Capacidade de Aquisição de imagens Faixas de $11 \mathrm{~km} \times 100 \mathrm{~km}$ até $11 \mathrm{~km} \times 1000 \mathrm{kmMosaicos}$ de até $12.000 \mathrm{~km}^{2}$ e $20.000 \mathrm{~km}^{2}$ de área imageada numa passagem; Freqüência de Revisita 2.9 dias a $1 \mathrm{~m}$ de resolução. Esses valores valem para latitude de $+/-40^{\circ}$. A freqüência de revisita para latitudes maiores.

Fonte: http://www.engesat.com.br/index.php?action=read\&news_id=494\&system=news. Acesso em 22 de Maio de 2011.
}

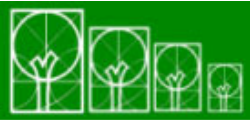

$\mathbf{S} \cdot \mathbf{B} \cdot \mathbf{A} \cdot \mathbf{U}$ Soc. Bras. de Arborização Urbana

REVSBAU, Piracicaba - SP, v.7, n.1, p. 52-75, 2012 
Figura 2 - Esquema de classificação para a cobertura vegetal urbana.

Figure 2 - Classification scheme to urban vegetation.

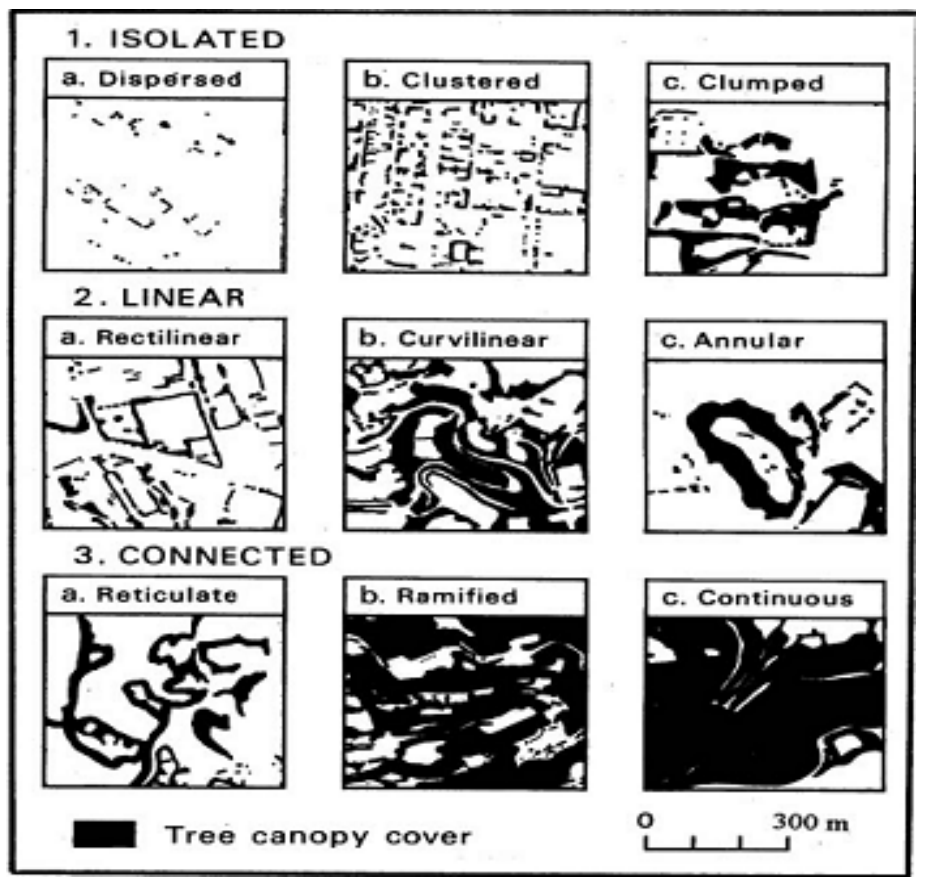

Fonte: $\operatorname{Jim}(1989)$.

EX:

Área total do bairro $100 \%$

Área total de vegetação do bairro $\mathrm{X}$

\section{$X=$ Área total de vegetação $\times 100=$ ICV}

Área total do bairro

\section{RESULTADOS E DISCUSSÕES}

Índice de cobertura vegetal (ICV) e Índice de cobertura vegetal por habitante (ICVH) do bairro Tenoné

O mapeamento da cobertura vegetal de porte arbóreo visível a olho nu foi baseado em imagem de satélite e fotografias aéreas dos anos de 1998, 2006 e 2010. Para o cálculo do ICV levou-se em consideração a área total do bairro, onde dividimos esse valor pela área

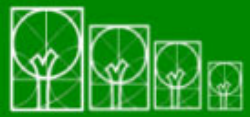

$\mathbf{S} \cdot \mathbf{B} \cdot \mathbf{A} \cdot \mathbf{U}$ Soc. Bras. de Arborização Urbana 
total de cobertura vegetal de cada ano correspondente, esse cálculo é feito a partir de uma regra de três básica.

Após o mapeamento, foi calculado o índice de cobertura vegetal por habitante que teve o seguinte processo - dividir a área coberta por vegetação pelo número de habitantes do bairro, tomando como base os dados do censo demográfico do Instituto Brasileiro de Geografia e Estatística (IBGE).

Quadro síntese de cobertura vegetal e índice de cobertura vegetal por habitante.

Summary table of land cover and vegetation index per inhabitant.

Índice de Vegetação e de Vegetação por Habitante.

Vegetation Index and vegetation per inhabitant.

\begin{tabular}{|c|c|c|}
\hline ANO & ICV & ICVH \\
\hline 1998 & $54,09 \%$ & $223,64 \mathrm{~m}^{2} / \mathrm{hab}$ \\
\hline 2006 & $41,98 \%$ & $173,56 \mathrm{~m}^{2} / \mathrm{hab}$ \\
\hline 2010 & $36,12 \%$ & $149,35 \mathrm{~m}^{2} / \mathrm{hab}$ \\
\hline
\end{tabular}

Os dados encontrados nesta pesquisa nos mostram que o bairro Tenoné vem passando por um momento de grande transformação no que diz respeito à infra-estrutura e a perda de cobertura vegetal ao longo dos últimos anos. Em relação ao ICV, encontramos para o ano de 1998 um percentual de 54,09\% de vegetação. Para o ano de 2006 esse valor foi de $41,98 \%$ e para o ano de 2010 foi de $36,12 \%$ ou seja, uma perda de $17,97 \%$ de cobertura vegetal ao longo de 12 anos.

É importante enfatizar que os órgãos competentes com o planejamento da cidade exerçam um controle com mais seriedade em relação ao uso do solo, pois a boa conservação dos espaços verdes influencia diretamente no conforto térmico para a população residente e conseqüentemente melhora a qualidade de vida.

Neste contexto o processo de expansão urbana verificada a partir da década de 1980 refletiu e reflete na forma da organização dos diferentes usos do solo do bairro, ou seja, os diferentes atores sociais modelam o espaço a partir de seus interesses individuais o que acaba por segregar uma parcela da população de menor poder aquisitivo.

A cobertura vegetal encontrada no bairro se configura na sua grande maioria por um padrão concentrada ou conectada (Jim, 1989) em espaços privados de usos restritos, sendo assim pouco evidenciadas as formas isoladas e lineares de vegetação. Observamos 
modificações na configuração em função da dinâmica da ocupação. Neste sentido nos últimos anos a vegetação do Tenoné vem se reduzindo em virtude da intensa ocupação através das construções legais de conjuntos habitacionais populares e condomínios fechados e ilegais como as ocupações espontâneas o que vem acarretando em significativa perda de espaços arborizados.

Após Observações nos mapas sobre a configuração espacial da cobertura vegetal, percebemos que para o ano de 1998 apresenta extensas manchas de vegetação conectadas no setor NNE do bairro, a extensa mancha a $N E$ corresponde à área do Bioparque Amazônia (figura 3). O Bioparque Amazônia Crocodilo safári zoo foi idealizado em 1989 pelo Dro Jorge Arthur Aarão Monteiro, possui característica pouco alterada do bioma Amazônico com vegetação nativa da região com grande variedade de espécies. A vegetação exótica também é encontrada no parque, sendo destaque entre elas a espécie Mangífera Indica (Mangueira), entre as espécies nativas cabe destacar a grande quantidade da espécie Euterpe oleracea (Açaizeiro) constituindo um grande mosaico vegetacional.

No parque podemos encontrar vegetação de terra firme e vegetação de várzea já que o mesmo se encontra em uma cota altimétrica de 10 e 5 metros de altitude. Se levarmos em consideração a função ecológica do local, o mesmo cumpre todas as atribuições sobre a qualidade de vida e no conforto ambiental da população residente no entorno do parque, em virtude da grande quantidade de cobertura vegetal. Mas, se levarmos em consideração a função social do parque, o mesmo não exerce essa atribuição em virtude do preço que é cobrado para visitação que, de certa forma exclui uma grande quantidade de pessoas que moram próximo ao parque como também do bairro.

O índice de cobertura vegetal do parque foi de 92,12\% para o ano de 2006 o que demonstra a grande quantidade de verde que é encontrado no local. Em relação à forma espacial da vegetação encontrada a mais evidenciada é a do tipo conectada (Jim, 1989), caracterizada por extensas manchas de vegetação, o que pode ser visualizado no mapa de cobertura vegetal do parque. figura 3. 
Figura 3 - Mapa de cobertura vegetal do Bioparque Amazônia, ano 2006.

Figure 3 - Vegetation map of the Bioparque Amazonia, year 2006.

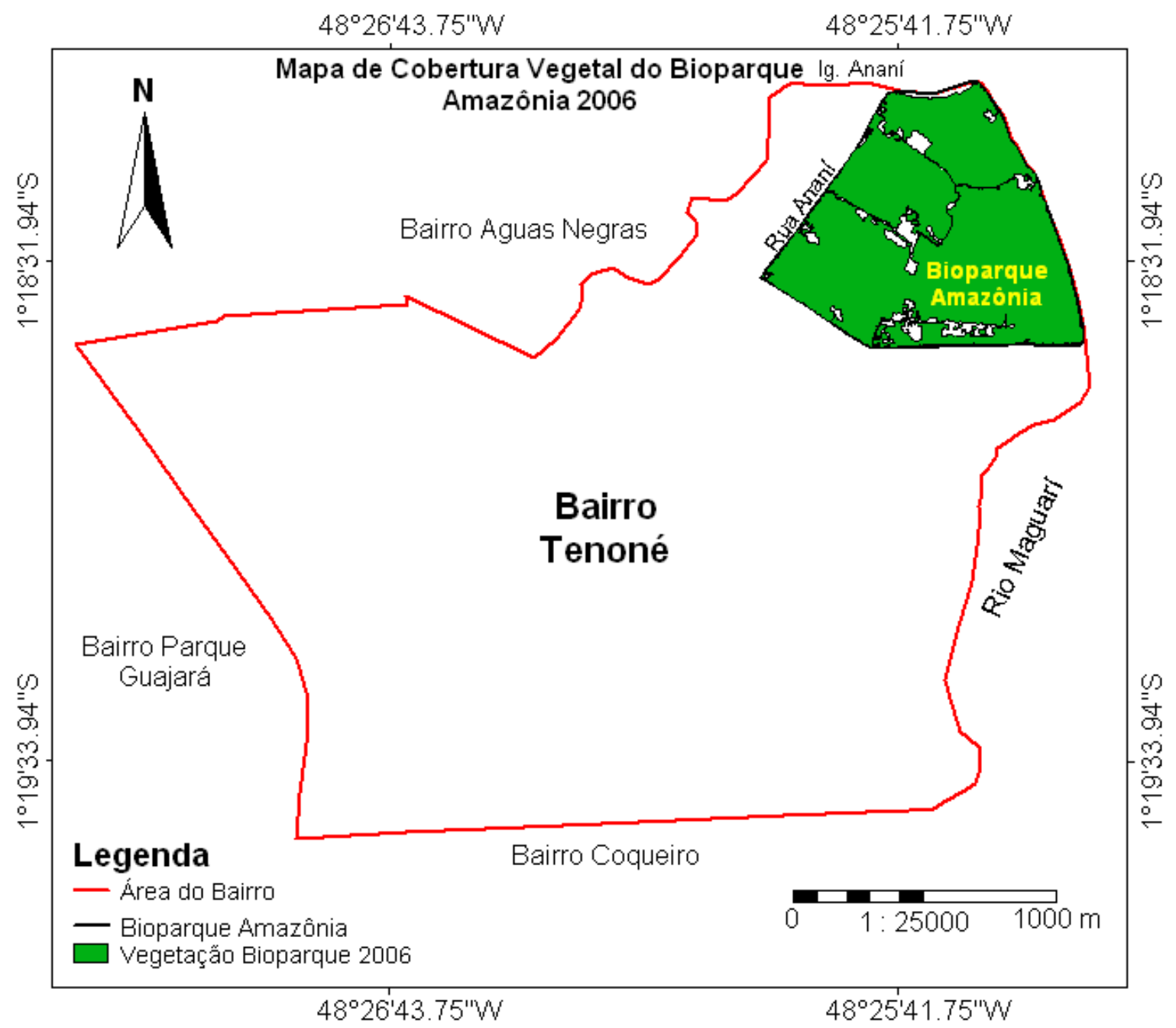

Fonte: Base cartográfica imagem de fotografias aéreas do município de BelémOrtofotos (cedida pela CODEM, 1998). Projeção UTM; DATUM SAD 69

Na figura 4, 5 e 6 observamos o mapa de cobertura vegetal dos anos de 1998, 2006 e 2010, respectivamente através destes mapas é possível observar que a cobertura vegetal ainda se faz muito presente na configuração espacial da área em estudo o que nos possibilita dizer que a população residente é beneficiada pelas atribuições que a cobertura vegetal exerce no espaço urbano, o que não significa dizer que a qualidade de vida da maior parte da população é boa, pois os diversos fatores tais como a infra-estrutura também são levados em consideração para uma boa qualidade de vida. 
Figura 4 - Mapa de cobertura vegetal do ano de 1998.

Figure 4 - Vegetation map of 1998

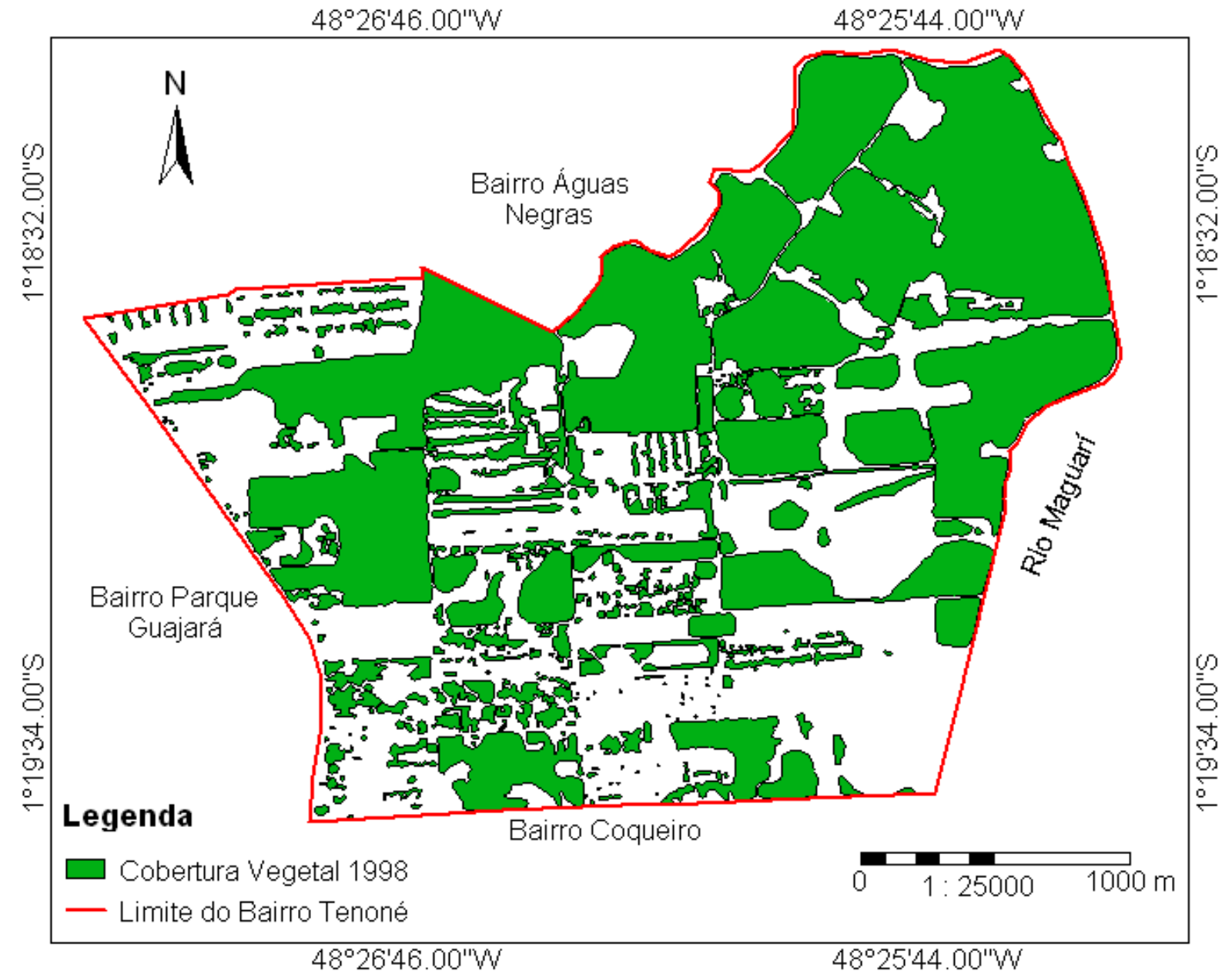

Fonte: Base cartográfica imagem de fotografias aéreas do município de Belém - Ortofotos (cedida pela CODEM, 1998). Projeção UTM; DATUM SAD 69

Para o ano de 2006 a configuração espacial da vegetação sofre mudanças significativas aparecendo à forma isolada na área de influencia da Rod. Augusto Montenegro, e aumento de áreas de ausência total da vegetação no setor $S E$ do bairro como pode ser observado na figura 4. Nota-se também que, ainda permanece uma extensa mancha de vegetação conectada no setor NE em virtude do Bioparque Amazônia. 
Figura 5 - Mapa de cobertura vegetal do ano de 2006.

Figure 5 - Vegetation map of 2006.

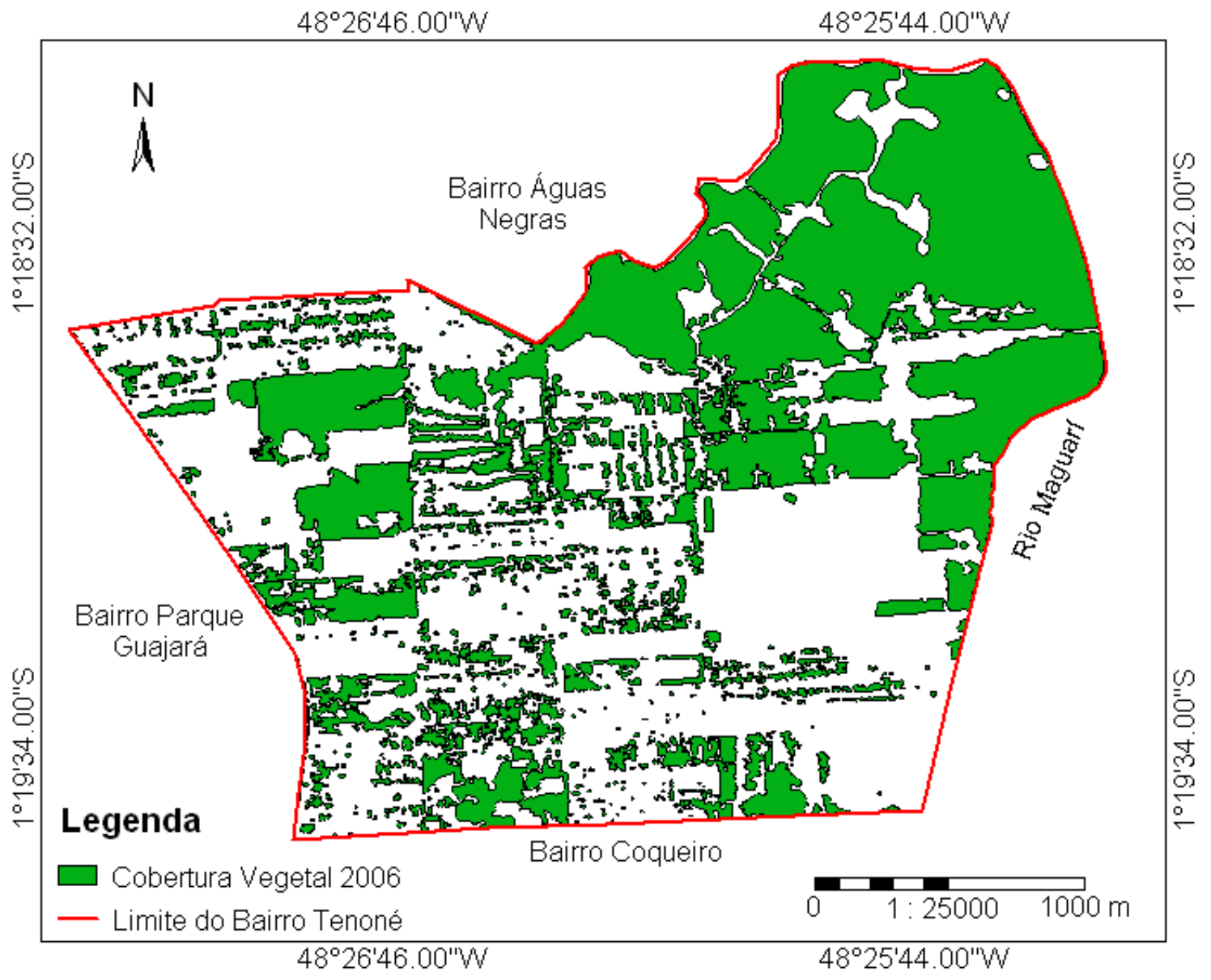

Fonte: Base cartográfica imagem lkonos 2006 (cedida pelo SIPAM) Projeção UTM; DATUM SAD 69

Para o ano de 2010 a configuração espacial da cobertura vegetal muda de maneira muito rápida em função da expansão urbana da cidade de Belém. Há uma extensa redução das manchas de vegetação conectada a $N E$, e aumento das áreas de ausência em demais setores principalmente no setor $O, S$ e $S E$. Essas áreas do bairro receberam nos últimos anos uma grande quantidade de projetos habitacionais para construção de casas populares e condomínios fechados o que pode de certa forma explicar a retração da cobertura vegetal da paisagem do bairro.

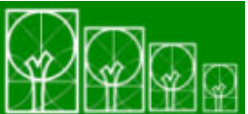

$\mathbf{S} \cdot \mathbf{B} \cdot \mathbf{A} \cdot \mathbf{U}$ Soc. Bras. de Arborização Urbana 
Figura 6 - Mapa de cobertura vegetal do ano de 2010

Figure 6 - Map of vegetation of 2010.

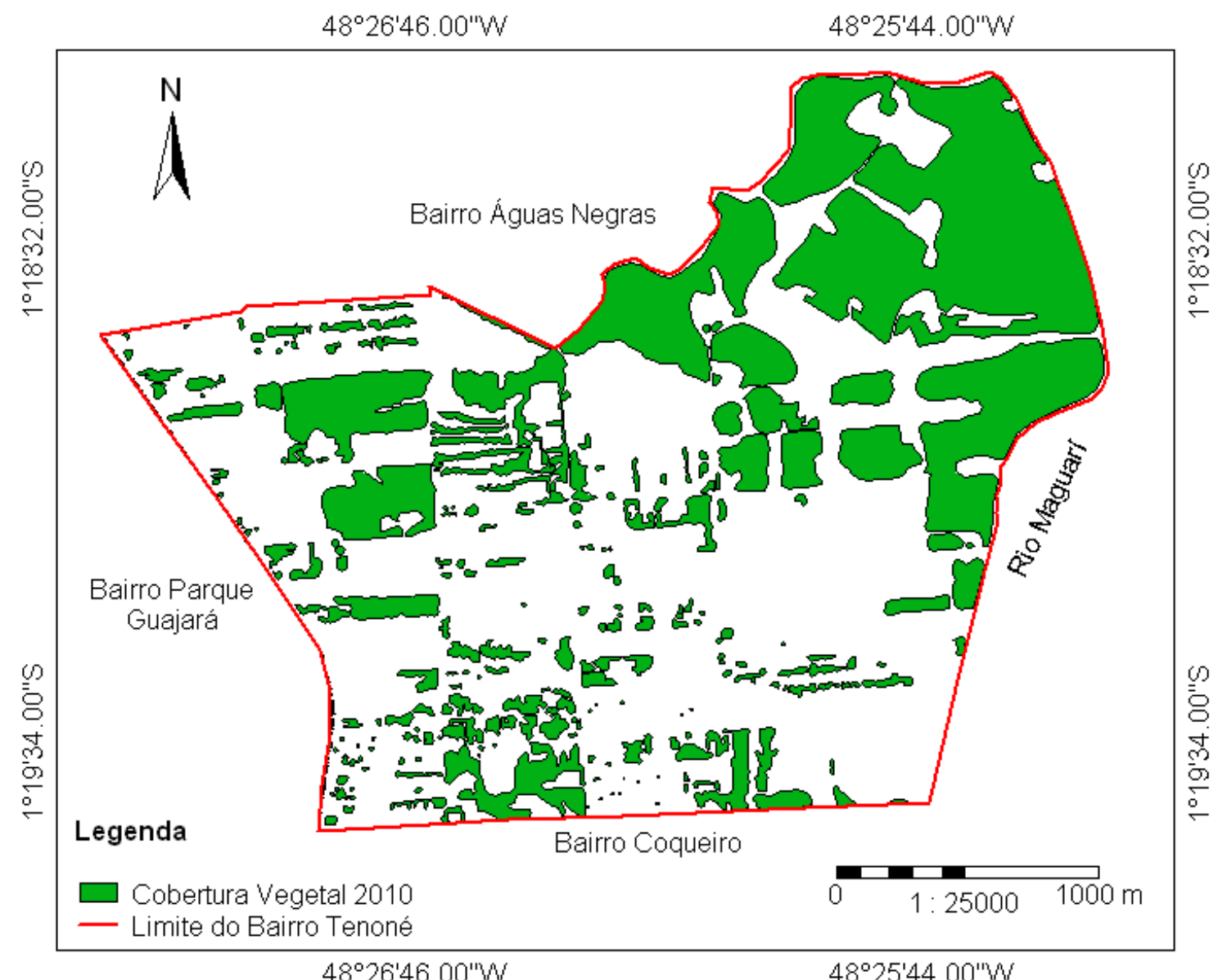

$48^{\circ} 26^{\prime} 46.00^{\prime \prime} \mathrm{W}$

$48^{\circ} 25^{\prime} 44.00^{\prime \prime} \mathrm{W}$

Fonte: Base cartográfica imagem Google 2010 (satélite Landsat 7 ETM+) Projeção UTM; DATUM SAD 69

O bairro Tenoné apresenta em suas características estruturais uma diversidade de formas de construções que se mesclam configurando um espaço com intensas relações sociais conflitantes e ao mesmo tempo segregadas, mas também um espaço privilegiado para populações que moram em condomínios fechados que dispõe de toda uma infraestrutura adequada para uma boa qualidade de vida social e ambiental. Por outro lado a exclusão se revela em ocupações irregulares que se configuram como uma forma particular de organização do espaço e de suas moradias.

Neste contexto é importante enfatizar que além do problema social, o bairro também possui muitos problemas ambientais, problemas esses relacionados aos corpos hídricos que cortam o bairro que se apresenta em situação precária de assoreamento e poluição se 
considerado o Igarapé Maguarí. Em trabalhos de campo constamos que o Igarapé Anani ainda apresenta suas características pouco alteradas pela ação humana o que não é o caso do Igarapé Maguarí onde constatamos a má qualidade de suas águas em virtude do lançamento de dejetos domésticos e a grande ocupação irregular em suas margens comprometendo a qualidade ambiental do local.

Neste sentido podemos afirmar que o processo de ocupação e uso do solo do bairro Tenoné vem se configurando de maneira diferenciada no espaço, sobretudo sem a preocupação de planejamento (exceto nos condomínios fechados) adequado o que influencia de forma negativa no equilíbrio entre os componentes naturais e artificiais, uma vez que o processo de urbanização em curso está provocando uma relativa escassez da cobertura vegetal que ali existe.

É importante destacar que a paisagem urbana do bairro Tenoné deixa claro o descaso do poder público com questões fundamentais de interesse da população, que passam sem a devida percepção da mesma, para a qualidade social e ambiental. Diante disto, os resultados do cálculo dos índices de cobertura vegetal (ICV) e de cobertura vegetal por habitante $(\mathrm{ICVH})$ nos possibilitou fazer uma análise bem detalhada sobre a qualidade ambiental da área em estudo, com a utilização de dados sobre a população residente no local, com cerca de 15. 894 habitantes (IBGE, 2000), e da área de vegetação existente nos anos de 1998 (3.554.665,79 m²), $2006\left(2.758 .611,12 \mathrm{~m}^{2}\right)$ e $2010\left(2.373 .927,39 \mathrm{~m}^{2}\right)$ respectivamente.

O resultado do índice de cobertura vegetal (ICV) do bairro Tenoné foi de 54,09\% para o ano de 1998, 41,98\% para o ano de 2006 e 36,12\% para o ano de 2010 respectivamente. Através desses dados é possível dizer que esses índices estão acima do recomendável para a cobertura vegetal, no qual o percentual é de $30 \%$, que de acordo com Lombardo (1985) é suficiente para proporcionar adequado balanço térmico. Em estudos realizados no Brasil e, sobretudo em bairros mais centrais da cidade de Belém acerca da importância da vegetação, mostram que em algumas localidades o índice de cobertura vegetal está abaixo do recomendado, o que nos permite dizer que a vegetação não possui um devido planejamento dentro do espaço urbano. Observe o Gráfico 1 abaixo ${ }^{7}$ :

\footnotetext{
${ }^{7}$ Os dados dos bairros Cremação, Parque Verde, Pedreira, Marambaia e Tenoné mostrados no gráfico abaixo estão baseados no ano de 2006, segundo imagem de satélite Ikonos (2006).
} 
Gráfico 1 - Comparação da Cobertura Vegetal entre Bairros.

Chart 1 - Comparison of Vegetation between Neighborhoods.

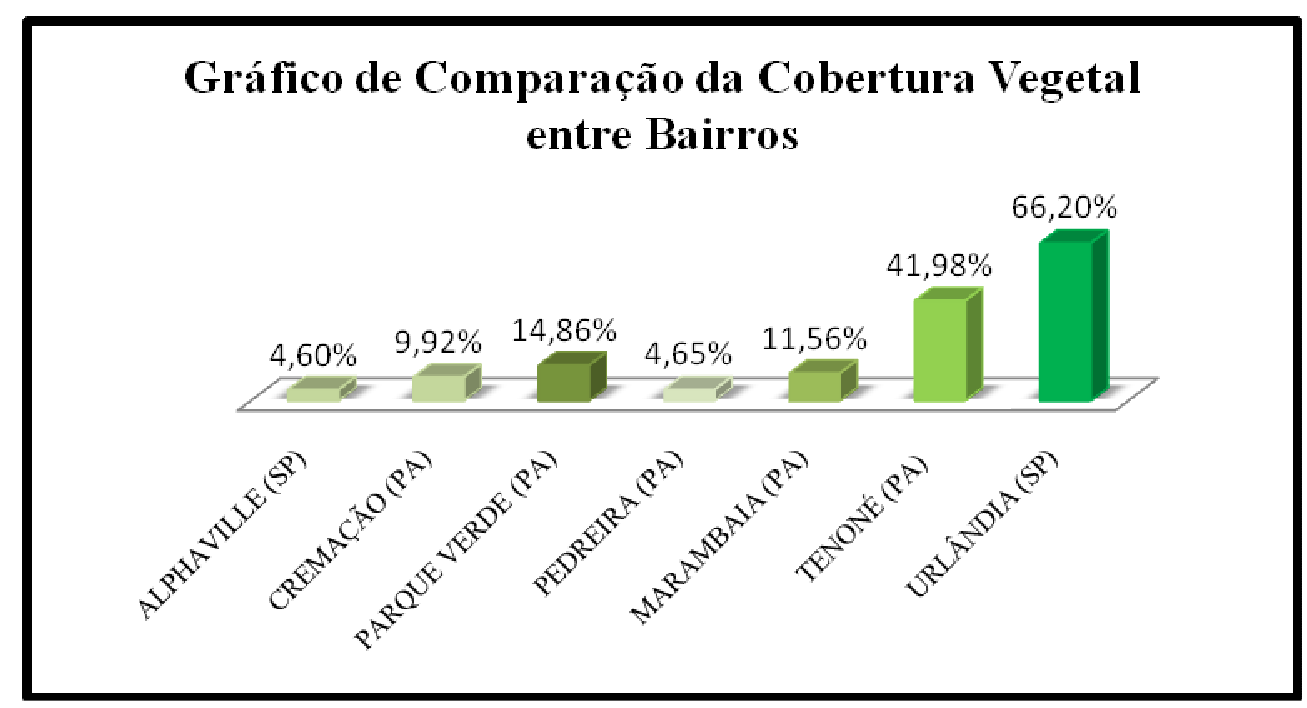

Entre as espécies existentes no bairro, ainda podemos encontrar remanescentes florestais de vegetação de várzea como: Euterpe oleracea - Açaizeiro e Mauritia Flexuosa Buriti, espécies nativas da região amazônica, e vegetação urbana como a Mangífera indica - Mangueira espécie exótica originária da Índia, Ficus Benjamina - Figueira. 
Figura 7 - Espécie Euterpe oleracea (Açaizeiro), encontrada na Rua Anani as margens do Igarapé Anani ao norte do bairro - vegetação conectada.

Figure 7 - Euterpe oleracea species (açaí), found on the Street Anani next to Igarapé Anani north of the neighborhood - connected vegetation.

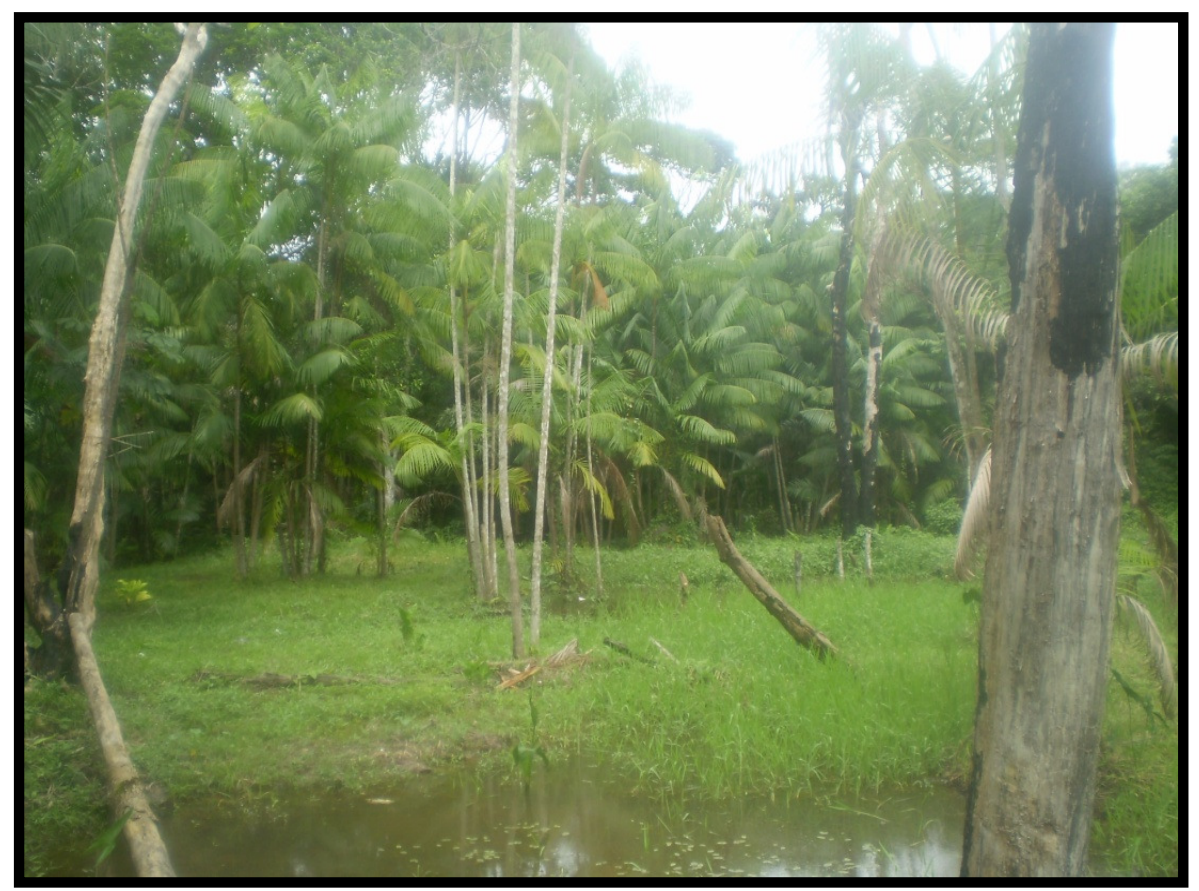

Fonte: ARAUJO, trabalho de campo. 2011. 
Figura 8 - Espécie Mangífera indica (Mangueira), encontrada na Rua um (conjunto Tenoné II) - vegetação isolada

Figure 8 - Mangífera indicia species (hose), found in the street (set Tenoné II) - alone vegetation .

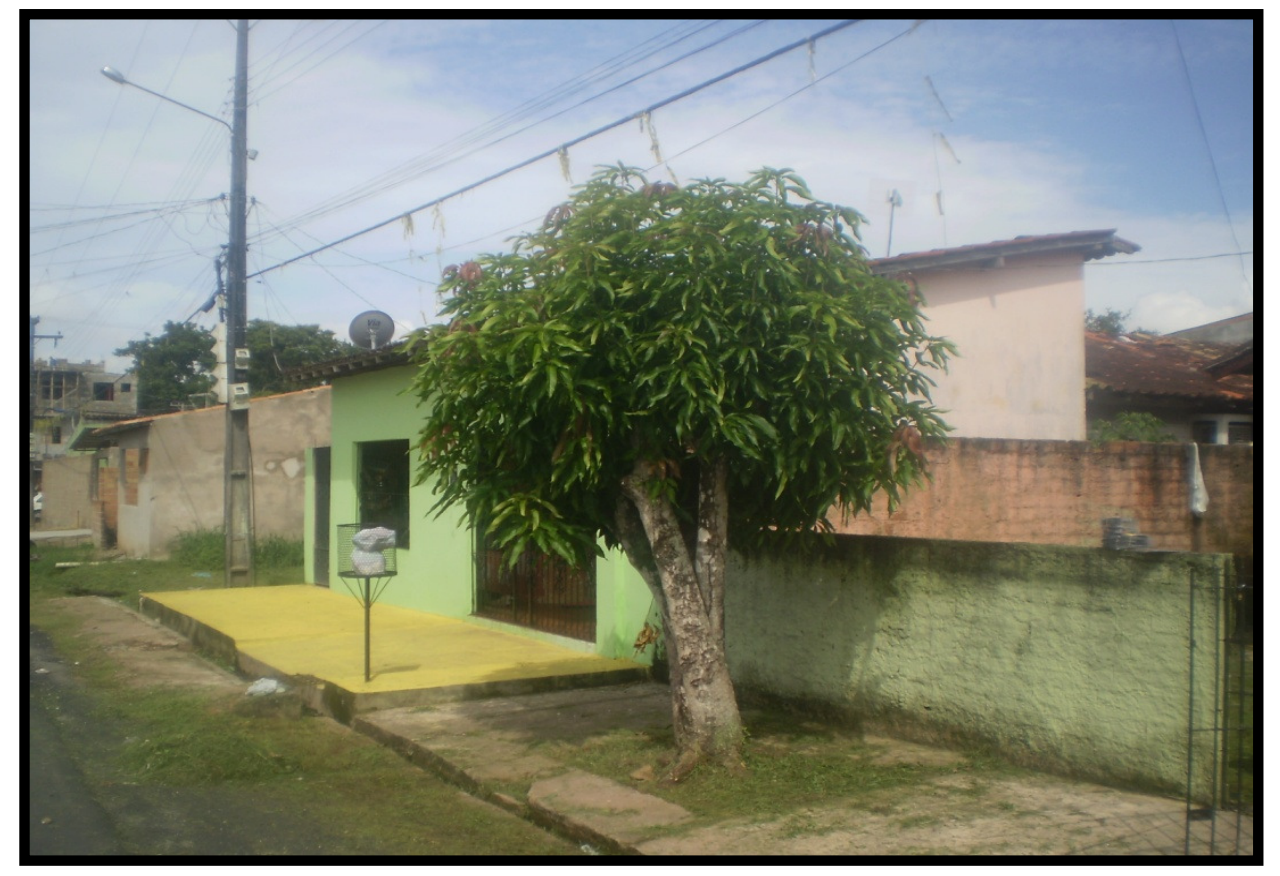

Fonte: ARAUJO, trabalho de campo. 2011.

Em relação aos resultados do índice de cobertura vegetal por habitante encontramos para o ano de $1998\left(223,64 \mathrm{~m}^{2} / \mathrm{hab}\right), 2006\left(173,56 \mathrm{~m}^{2} / \mathrm{hab}\right)$ e para o ano de 2010 $\left(149,35 \mathrm{~m}^{2} / \mathrm{hab}\right)$. Apesar dos dados nos parecerem à primeira vista satisfatórios não podemos dizer que o bairro apresenta uma boa qualidade ambiental para a totalidade da população, uma vez que a maior parte da vegetação encontra-se em áreas de propriedade privada.

De acordo com a política ambiental do município de Belém que enfatiza uma intervenção nos sistemas de drenagem, o manejo de resíduos sólidos e a educação sanitária e ambiental a mesma não se faz presente no cotidiano dos moradores do bairro Tenoné, principalmente a política sobre a educação ambiental que é de fundamental importância no sentido de esclarecer à população sobre os benefícios de se preservar as áreas verdes do bairro, já que o mesmo não possui espaços de lazer livre públicos como praças, parques e jardins. 


\section{CONCLUSÕES}

Pelo trabalho realizado no bairro do Tenoné no município de Belém é possível concluir que é muito importante a adoção de políticas públicas do ponto de vista ambiental que tenham como objetivo a preservação do verde urbano, pois a partir de vários estudos é evidente os vários benefícios da vegetação para a qualidade de vida e ambiental das populações. Fica evidente através deste estudo que o bairro não possui um planejamento urbano adequado e se configura como uma área que possui uma infra-estrutura deficiente com poucas áreas verdes e de lazer.

Em relação aos índices destacam-se o elevado percentual para os anos de 1998 (54,09\%), 2006 (41,98\%) e para o ano de 2010 (36,12\%) de vegetação total da área do bairro. Através das pesquisas de campo, foi possível observar um novo e crescente interesse por áreas verdes no bairro Tenoné, principalmente pelos agentes imobiliários, pois a valorização das áreas verdes não é apenas uma imposição do mercado imobiliário, mas faz parte de um contexto maior, uma nova racionalidade, promovida também pela população, que deseja morar perto do verde.

O índice de cobertura vegetal se manteve suficiente até o ano de 2010 em virtude do bairro possuir um processo de ocupação urbano relativamente recente, se comparada com outros bairros centrais da cidade. De acordo com a classificação da cobertura vegetal proposta por (Jim, 1989) constatou-se que a forma que mais se apresenta no bairro é conectada em virtude de grandes sítios bem arborizados que são encontrados no local de estudo.

Apontamos aqui a necessidade de criação pelos órgãos competentes de áreas verdes de lazer como, por exemplo, as praças e parques públicos uma vez que esses espaços não são encontrados no bairro e que são importantes tanto para o lazer como para a estética do espaço e conseqüentemente para uma boa qualidade de vida para a população. Enfatizamos a necessidade de um ordenamento adequado para a cobertura vegetal de ruas, avenidas e logradouros, pois são importantes na proporção de sombra para os transeuntes que circulam pelas vias públicas do bairro. É importante que se preserve as áreas verdes já existentes no bairro, pois através dos cálculos realizados observou-se a diminuição gradativa desses espaços, que pode está atrelada a intensificação da urbanização da região metropolitana de Belém verificado, sobretudo a partir da década de 1980.

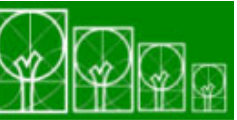

$\mathbf{S} \cdot \mathbf{B} \cdot \mathbf{A} \cdot \mathbf{U}$ Soc. Bras. de Arborização Urbana 


\section{REFERÊNCIAS}

BELÉM (Município, 2008). Lei no 8.655, 30 de jul. 2008. Dispõe sobre o Plano Diretor do Município de Belém, e dá outras providências. Disponível em: <http//www.prefeituradebelem.com.br/>. Acesso em: 22 de Mai. 2011.

BEZERRA, Adenilson Francisco. Qualidade Ambiental Urbana do Distrito Baeta Neves, Município de São Bernardo do Campo (SP). 2008. 132f. Dissertação (Mestrado em Geografia) - Programa de pós-graduação em Geografia Física, do Departamento de Geografia da Faculdade de Filosofia, Letras e Ciências Humanas -FFLCH- Universidade de São Paulo, São Paulo, 2008.

BUCCHERI FILHO, Alexandre Theobaldo e NUCCI, João Carlos. Espaços Livres, Áreas verdes e Cobertura Vegetal no Bairro Alto da XV, Curitiba/PR. Geousp, São Paulo, v. 18. p. 48-59, Jun/Set. 2006.2 Disponível em: <http://citrus.uspnet.usp.br/rdg/ojs/index.php/rdg/article/view/34/25>. Acesso em: 10 de Abr. 2011.

CORRÊA, Nívia Berna da Silveira e COSTA, Suellen Cristina Vidal. Qualidade Ambiental em Áreas de Expansão Urbana: Um Estudo de Caso Sobre a Perda da Cobertura Vegetal do Bairro Parque Verde - Belém/PA; Trabalho Acadêmico de Conclusão (graduação em licenciatura em Geografia), Belém: IFPA, 2009. 81p.

IBGE, Instituto brasileiro de Geografia e Estatística: censo demográfico do ano 2000. Disponível em: http://www.ibge.gov.br. Acesso em 25 de Março de 2011.

IWATA, Bruna de Freitas. Diagnóstico Sobre o Confronto Entre a arborização e o Planejamento Urbano no Bairro vermelha em Teresina/PI In: II Congresso de Pesquisa e Inovação da Rede Norte e Nordeste de Educação Tecnológica, 6, 2007. João Pessoa/PB. Anais. II Conep, 2007. Disponível em: <http://www.redenet.edu.br>. Acesso em: 25 de Jan. 2010. 
JIM, C. Y. Tree-canopy characteristics and urban developmente in Hong Kong. The Geographical Review, v.79, n.2. Lawrence: American Geographical Society, 1989. p. 210255.

LOMBARDO, M. A. Ilha de calor nas metrópoles: O exemplo de São Paulo. São Paulo: Hucitec, 1985.

LUZ, L.M, RODRIGUES, J. E. C e FIGUEIREDO, V. L. M. Avaliação da Qualidade Ambiental Urbana do Município de Belém com Base na Dinâmica Espacial da Cobertura Vegetal In: IV Seminário Latino Americano de Geografia Física, 8. 2006. Maringá/PR. Anais. Maringá/PR: UEM, 2006.

NUCCI, João Carlos, CAVALHEIRO, Felisberto. Cobertura Vegetal em Áreas Urbanas: Conceitos e Métodos. Geousp, São Paulo, v. 6. p. 29-36, 1999. Disponível em: <http://www.geografia.fflch.usp.br/publicacoes>. Acesso em: 10 de Jun. 2011.

PIVETTA, Kathia Fernandes Lopes e SILVA FILHO, Demóstenes Ferreira da Silva. Boletim Acadêmico: Série Arborização Urbana; Jaboticabal/SP, UNESP/FCAV/FUNEP, 2002.

VENTURA, Thais Bircak e FÁVERO, Oriana Aparecida. Estudo da Cobertura Vegetal dos Bairros de Alphaville e Tamboré (Santana de Parnaíba/SP) In: XI Simpósio de Geografia Física Aplicada, 14, 2005. São Paulo. Anais. São Paulo: Tarik Rezende de Azevedo, 2005. CD-ROM. 